\title{
EIIdA
}

\section{Revista Eletrônica de Estudos Integrados em Discurso e Argumentação}

\section{ARGUMENTAÇÃO, ESTILO E ETHOS DISCURSIVO NO DISCURSO LITERÁRIO: O POEMA CADA VEZ MAIS, DE RODRIGO BRÓ EM FOCO}

\section{Sandro Luis da Silva ${ }^{i}$}

Resumo: Este artigo, de acordo com o quadro de práticas discursivas, tem como objetivo analisar a constituição do ethos (dos ethé) discursivo(s) no poema "Cada vez mais" de Rodrigo Bró, poeta mineiro. Considerando ethos, argumentação e estilo, nossa hipótese é que, pela análise desses elementos presentes no poema e marcados pela cenografia (MAINGUENEAU, 2008, 2010, 2011, 2015, 2016) - sobretudo na exteriorização do discurso dos enunciados em poema cujo tema é a busca incessante do enunciador pela plenitude de sua existência - é possível identificar na poesia de Bró a marca de uma busca incessante do ser humano, trilhada por caminhos que caracterizam o adensamento de suas experiências que renovam na cenografia contemporânea o debate, a reflexão, o posicionamento do enunciador acerca do comprometimento entre a poesia e o sentimento humano, muitas vezes antagônico em sua própria essência.

Palavras-chave: Estilo. Ethos. Discurso. Argumentação.

Abstract: This article, considering the framework of discursive practices, aims to analyze the constitution of ethos (discursive ethé) in the poem Cada vez mais... Rodrigo Bró, poet from Minas Gerais. Interweaving ethos, argumentation and style, our hypothesis is that, through the analysis of these elements present in the poem and marked by the scenography (MAINGUENEAU, 2008, 2010, 2011, 2015, 2016) especially in the exteriorization of the speech of statements in poems whose theme is the search of the enunciator by the fullness of its existence. - it is possible to identify in Bró's poetry the mark of an incessant search of the human being, traced by paths that characterize the density of his experiences that renew in contemporary scenography the debate, the reflection, the positioning of the enunciator about the compromise between poetry and human feeling, often antagonistic in its own essence.

Keywords: Style. Ethos. Speech. Argumentation.

\footnotetext{
i Doutor em Língua Portuguesa pela Pontifícia Universidade Católica de São Paulo (PUC/SP). Professor Adjunto de Língua Portuguesa no Departamento de Letras da Universidade Federal de São Paulo (UNIFESP). E-mail: vitha75@gmail.com.
} 
EID\&A - Revista Eletrônica de Estudos Integrados em Discurso e Argumentação, Ilhéus, n. 13, jan/jun.2017.

\section{Palavras iniciais...}

É fato que a sociedade é permeada por diferentes discursos, os quais estabelecem várias relações entre os sujeitos. No entanto, o conceito de discurso implica certa complexidade. Maingueneau (2008, 2013, 2015), ao longo de suas obras, discute, por exemplo, as relações que se fazem entre discurso, frase, língua, texto, enunciado, apontando os valores clássicos que esses termos assumiram para a Linguística.

Existem vários tipos de discurso, como literário, médico, jornalístico, jurídico, pedagógico, cada qual com suas peculiaridades. Agrupar discursos quanto ao seu estilo implica fundar situações específicas da comunicação de uma sociedade e de suas invariantes enunciações, gerando a partir dessa divisão uma categoria discursiva.

Em relação ao discurso literário, no qual se encontra o corpus deste artigo, seu conceito ainda é bastante problemático, conforme indica Mainguenau (2006). O discurso literário enquadra-se na categoria dos discursos constituintes que "designa fundamentalmente os discursos que se propõem como discursos de origem, validados por uma cena de enunciação que autoriza a si mesma" (MAINGUENEAU, 2006, p. 60).

$O$ autor francês lembra ainda que o discurso inscreve-se em gêneros do discurso, que são considerados dispositivos de comunicação, situados histórica e socialmente. Os gêneros, para o autor, estão ligados às necessidades do dia a dia das pessoas, fato que não pode ser ignorado pelo analista do discurso. Segundo Maingueneau (2013, p. 67), "os gêneros de discurso pertencem a diversos tipos de discurso associados a vastos setores da atividade social".

Ao pensar o discurso e os gêneros discursivos, vários são os conceitos que podem ser suscitados. Dentre eles, é possível citar o ethos discursivo, argumentação e o estilo. Para entender esses termos, faz-se necessário pensar o conceito de discurso, entendido, nos limites deste artigo, como um espaço caracterizado pela singularidade, o qual se encontra na exterioridade da língua, no cerne da vida social.

Este artigo objetiva apresentar uma análise do ethos discursivo (ou ethé discursivos) presente no poema "Cada vez mais", de Rodrigo Bró, autor mineiro, que tem dedicado versos para tratar de sentimentos do homem, além da temática envolvendo a natureza, acrescentando em seus versos tom de sensualidade. Poesia marcadamente metafórica, procura extravasar todo o 
EID\&A - Revista Eletrônica de Estudos Integrados em Discurso e Argumentação, Ilhéus, n. 13, jan/jun.2017.

sentimento do ser humano angustiado dentro de uma sociedade individualista, presa ao materialismo imposto pelos padrões burgueses. Verificam-se, por meio da materialidade discursiva, os mecanismos linguísticos que levam à (des)construção do ethos discursivo dos enunciados no poema do autor, focalizando o modo enunciativo de organização do discurso (MAINGUENEAU, 2008, 2010, 2013, 2015).

Algumas questões motivaram este estudo: É possível reconhecer a imagem que o enunciador (eu lírico) do texto literário, no caso, o poema "Cada vez mais" de Rodrigo Bró, faz de si a partir de suas escolhas linguísticas? Como essas escolhas podem ser observadas sob a perspectiva linguístico-discursiva? Como as concepções contemporâneas sobre o ethos discursivo, sobretudo as defendidas por Maingueneau, esclarecem o funcionamento das interações verbais no texto literário?

Durante o processo de interação, imagina-se que os recursos linguísticos utilizados pelo enunciador podem aparecer sob diversas estruturas, as quais podem ser detectadas na análise do texto. Supõe-se que as estratégias linguístico-discursivas para a manifestação do ethos discursivo no corpus escolhido para este artigo não sejam as mesmas para as diferentes vozes em interação presentes nos diferentes poemas produzidos pelo autor, publicados, sobretudo, no Blog Recanto das Letras, de onde extrai o poema objeto de análise deste artigo.

Objetivei, assim, focalizar as marcas linguísticas da enunciação e seu papel na identificação do ethos discursivo e na construção do texto. Busquei registrar os elementos estilísticos capazes de determinar a (des)construção do ethos na cena da enunciação.

Para atingir ao proposto, divido o artigo em duas grandes partes: na primeira, apresento uma revisão dos principais conceitos que sustentam a análise, que está na segunda parte. Por fim, trago as palavras finais e as referências.

\section{Um pouco de teoria...}

\subsection{O ethos discursivo}

Por conceber a linguagem como ação social, conforme postula Bakhtin (2003), os sujeitos estabelecem vínculos de comunicação entre si, uma vez que suas atividades se realizam na interação social. É através dessa ideia de 
EID\&A - Revista Eletrônica de Estudos Integrados em Discurso e Argumentação, Ilhéus, n. 13, jan/jun.2017.

interação que se define o aspecto básico da concepção de linguagem fundamentada no caráter dialógico (BAKTHIN, 2003).

Ao discutir sobre heterogeneidade discursiva, evoca-se a ideia da natureza histórica e social da linguagem. Ou seja, a natureza do fenômeno linguístico passa a ser concebida numa dimensão histórica e social e não individual. Nesses termos, Bakhtin (2003) concebe a linguagem não como um sistema abstrato, gramatical e homogêneo, mas sim como uma realidade viva, heterogênea, uma vez que é constituída e caracterizada pelas diversas vozes sociais.

De acordo com Amossy (2005), a apresentação de si no discurso não se limita a uma técnica apreendida, a um artifício, mas se efetua nas trocas verbais mais corriqueiras e pessoais. Todo ato de tomar a palavra implica a construção, deliberada ou não, de uma imagem de si. A autora assinala que a construção dessa imagem não se faz por meio de um autorretrato feito pelo enunciador, pelo detalhamento de suas qualidades ou porque ele fale explicitamente de si, mas que seu estilo, suas crenças, seus valores, suas ideologias implícitas são suficientes para construir a representação desse sujeito que enuncia.

De acordo com Maingueneau (2005), a construção da imagem de si não se restringe à eloquência judiciária ou mesmo à oralidade; pelo contrário: está presente em qualquer discurso, inclusive no escrito, uma vez que ele "possui uma vocalidade específica, que permite relacioná-lo a uma fonte enunciativa, por meio de um tom que indica quem o disse" (MAINGUENEAU, 2005, p. 72).

O termo ethos era designado pelos antigos como a construção de uma imagem de si no intuito de garantir o sucesso do empreendimento oratório (AMOSSY, 2005). O ethos, um dos componentes da Antiga Retórica, é definido como os traços de caráter que o orador deve mostrar ao auditório retomando, assim, as ideias de Aristóteles, que atribuía poder de persuasão do discurso ao seu caráter moral.

Inscrita na Análise do Discurso, a noção de ethos discursivo desenvolvida por Maingueneau (2005, p. 38) se difere da noção Aristotélica pertencente à tradição retórica; ela ultrapassa o quadro da argumentação, estudando a incidência do ethos discursivo "em textos não necessariamente de tipo argumentativo". Essa noção de ethos, segundo o autor, permite refletir sobre o processo mais geral da adesão de sujeitos a certa posição discursiva. Em termos mais pragmáticos, o autor propõe que o ethos não é dito explicitamente, mas se desdobra no registro do mostrado. Ele é vinculado ao 
EID\&A - Revista Eletrônica de Estudos Integrados em Discurso e Argumentação, Ilhéus, n. 13, jan/jun.2017.

exercício da palavra, ao papel que corresponde seu discurso, independente de seu desempenho oratório.

Dessa forma, a constituição do ethos ocorre no discurso, estando, portanto, ligado à enunciação, o que implica um envolvimento do enunciatário que também constrói representações prévias da imagem do enunciador. De acordo com Amossy (2005), a constituição da imagem de si é constitutiva da interação verbal entre os sujeitos discursivos e, na maioria das vezes, determina a capacidade de o enunciador agir sobre seus enunciatários. Desenvolvendo a ideia de Perelman de que o auditório é sempre uma construção do orador, Amossy (2005) afirma:

A construção discursiva do ethos se faz ao sabor de um verdadeiro jogo especular. $O$ orador constrói sua própria imagem em função da imagem que ele faz de seu auditório, isto é, das representações do orador confiável e competente que ele crê serem as do público. (AMOSSY, 2005, p. 124)

Entendo o ethos como um elemento argumentativo, uma vez que a sua constituição no e pelo discurso implica que se considere o discurso sob duas perspectivas, conforme Amossy (2005). A primeira, sendo a interacional, a qual já foi mencionada, mostrando que a eficácia discursiva dá-se no processo de interação verbal, de trocas entre os participantes. A segunda perspectiva é a institucional, segundo a qual essa troca entre os participantes não se dissocia das posições por eles ocupadas no campo religioso, político, intelectual, literário etc., no interior do qual atuam. De acordo com essa perspectiva, a ação que o enunciador exerce sobre seu enunciatário não é de ordem linguageira, mas social. Sua autoridade não resulta da imagem de si criada em seu discurso, mas do lugar de onde ele enuncia.

A construção do ethos discursivo não é puramente linguística, uma vez que a imagem de si é construída no e pelo discurso, nas trocas e diálogos entre os participantes, o que pressupõe também considerar o que é exterior ao discurso. É preciso considerar que o sujeito enunciador deve conferir determinado status a si próprio e ao enunciatário, para legitimar seu dizer e que este revela no discurso uma posição institucional marcando sua relação com o saber (MAINGUENEAU, 2005). O ethos discursivo é mais que uma postura que demonstra seu pertencimento a determinado grupo dominante, mais que uma manifestação linguística, ou autorretrato de bom caráter, a imagem de si construída no e pelo discurso com vistas a influenciar opiniões e atitudes. 
EID\&A - Revista Eletrônica de Estudos Integrados em Discurso e Argumentação, Ilhéus, n. 13, jan/jun.2017.

Compartilhando da proposta de Maingueneau (2008, p. 17) inscrita no quadro da Análise do Discurso, a noção de ethos discursivo em que se baseia a análise apresentada é:

1- uma noção discursiva, uma vez que ele se constrói através do discurso; não é uma "imagem" do enunciador exterior a sua fala;

2- fundamentalmente um processo interativo de influência sobre o outro;

3- uma noção híbrida (sócio-discursiva), um comportamento socialmente avaliado, que não pode ser apreendido fora de uma situação de comunicação precisa, integrada ela mesma numa determinada conjuntura sócio-histórica.

O ethos discursivo, assim, constitui-se em uma instância discursiva, construído no momento da enunciação.

\subsection{As cenas enunciativas}

A constituição do ethos discursivo, de acordo com Maingueneau (2015), exige que sejam consideradas as cenas (englobante, genérica e cenografia). 0 discurso literário está inserido na categoria dos discursos constituintes, assim como também o discurso religioso, o científico e o filosófico. Esses discursos representam o mundo e suas enunciações são partículas integrantes do mundo que representam. A pretensão dos discursos constituintes, segundo Maingueneau (2008), é de não reconhecer outros discursos acima dos seus. Para eles, não existe outra autoridade que não a deles, apesar de que há uma contínua interação entre discursos constituintes e não constituintes, bem como entre os próprios discursos constituintes. São assim designados, especialmente por serem discursos de Origem, validados por uma cena de enunciação.

O ethos de um discurso resulta da interação de alguns elementos constitutivos da construção da imagem de si, dentre eles, justamente, a cena de enunciação. Para Maingueneau (2006), os enunciados causam a adesão do leitor através de um modo de dizer (o estilo), que é também um modo de ser. Essa adesão ocorre por uma sustentação recíproca entre a cena de enunciação, da qual o ethos é parte constitutiva, e o conteúdo apresentado.

Como afirmei anteriormente, na concepção do autor, essa cena de enunciação está subdividida em três cenas, que ele propôs chamar: cena 
EID\&A - Revista Eletrônica de Estudos Integrados em Discurso e Argumentação, Ilhéus, n. 13, jan/jun.2017.

englobante, cena genérica e cenografia. A cena englobante relaciona-se ao tipo de discurso. Portanto, todo enunciado literário está inserido numa cena englobante literária.

Segundo o autor francês, "todo enunciado literário está vinculado a uma cena englobante literária, sobre a qual se sabe em particular que permite que seu autor use um pseudônimo, que os estados de coisas que propõe sejam fictícios etc." (MAINGUENEAU, 2006, p. 251).

A cena genérica está relacionada ao contrato associado a um gênero ou a um subgênero de discurso; poesia, prosa, romance, narrativa poética etc. A obra de Rodrigo Bró está inserida na cena genérica relativa ao gênero poesia. A obra é enunciada através de um gênero do discurso determinado e da qual é parte integrante. $O$ gênero não é exterior à obra, mas uma de suas condições, estando sujeita a um certo número de parâmetros, dispositivos de comunicação definidos, concebidos com a ajuda das metáforas do "contrato", "do ritual" ou "do jogo".

A cenografia é a cena da fala; ela se apresenta para além de toda cena de fala que seja dita no texto. Ela é construída no desenvolvimento do próprio texto já que não é imposta pelo gênero; é simultaneamente aquilo da qual emana o discurso e aquilo que esse discurso constrói, ela valida um enunciado que, por sua vez, deve validá-la. A cenografia, através dos conteúdos engendrados pelo discurso, permite especificar e validar o ethos. Através daquilo que diz, o mundo que representa, a obra tem de validar essa cenografia que ela mesma impõe desde o início.

De acordo com Carvalho (2011, p. 85),

A cenografia é aquela com a qual o coenunciador se confronta, corresponde ao contexto que a obra implica. Não se trata de um cenário ou de um quadro já construído e independente no interior de um espaço. Ao contrário, à medida que a enunciação se desenvolve, o seu dispositivo de fala vai sendo constituído. Trata-se, assim, da cena de fala que o discurso pressupõe para que possa ser enunciado. Esta cena se apoia na memória coletiva a fim de legitimar um enunciado e ao mesmo tempo ser legitimada por ele. Ela só se manifesta plenamente se mantiver certa distância em relação ao coenunciador, para que ela mesma controle seu desenvolvimento. Desse modo, a escolha da cenografia não se dá sem propósitos, uma vez que o discurso se desenvolve a partir dela, no intuito de conquistar a adesão com a instituição da cena enunciativa que o torna legítimo.

Em “Cada vez mais", de Rodrigo Bró, por exemplo, a cenografia é caracterizada pela estrutura poética moderna, versos livres e ausência de 
EID\&A - Revista Eletrônica de Estudos Integrados em Discurso e Argumentação, Ilhéus, n. 13, jan/jun.2017.

rimas, e imprimem uma breve e sutil apresentação na poesia. A cenografia, construída através do ritmo célere e da disposição curta dos versos, como mostraremos na análise, consolida-se pela utilização de enunciados curtos e isolados, sugerindo máximas ou aforismos, que produzem efeitos de apontamentos ou registros cotidianos de um homem que anota e enumera as suas reflexões, as suas observações e o seu aprendizado em seu dia a dia. Os versos estão dispostos de uma forma que confere ao texto uma cadência lenta, equilibrada e racional, sugerindo alguém que colhe, na observação atenta e detida do mundo e de si mesmo, aprendizados e vivências diárias, mas que não o satisfazem, nem ele - o enunciador, nem a pessoa amada; por isso está em busca de si "cada vez mais".

Contribui para esse efeito de sentido, também, a pontuação. Caracterizase, no texto de Bró, como demonstraremos na análise, apenas pela (rara) presença de vírgulas e pontos finais. A presença de vírgulas e pontos finais desencadeia as pausas necessárias para que o poema retrate a cadência que sugere a cenografia e que irá contribuir para a (des)construção do ethos discursivo.

\subsection{O estilo}

O estilo é um elemento que implica a construção da imagem de si. Segundo Cruz (2009), o ethos se define, também, pela recorrência de traços que permitem traçar um caráter, somado a um temperamento, a determinadas competências e um corpo, todos associados ao sujeito da enunciação. Esse caráter é definido em função do percurso que executa, da estratégia adotada para dizer, e não do que diz efetivamente.

Para Martins (2008), não há um consenso quanto à definição de estilo. Há, sim, muita dificuldade na classificação já que as características individuais podem incluir escolha, desvio da norma, elaboração, conotação. Acrescenta, ainda, que dos teóricos da estilística, alguns só consideram o estilo na língua literária, enquanto outros o consideram nos diferentes usos da língua. Enquanto uns relacionam o estilo ao autor, outros o relacionam à obra, outros o relacionam ao leitor que reage ao texto literário. Uns se concentram no enunciado e outros na forma da obra. Segundo a autora, a palavra estilo tem uma origem modesta, é oriunda do latim - stilus - e designava um instrumento pontiagudo que os antigos utilizavam para escrever sobre 
EID\&A - Revista Eletrônica de Estudos Integrados em Discurso e Argumentação, Ilhéus, n. 13, jan/jun.2017.

tabuinhas enceradas e daí passou a designar a própria escrita e o modo de escrever. No domínio da linguagem, são numerosas as definições de estilo.

A noção de estilo tem sido estudada por diversas áreas do conhecimento humano, sob as mais diferentes perspectivas teóricas. Autores ligados à Análise do Discurso apresentam uma visão que vai além da comum concepção romântica, abrigada na tradição estilística, que compreende o estilo como a expressão de uma subjetividade em que desvio da regularidade e escolha são utilizados com plena consciência. Dentro dessa concepção, segundo Possenti (2009), só haveria estilo quando houvesse um desvio da linguagem, desvio este decorrente de uma escolha consciente. Para ele, o estilo está no modo que o enunciador organiza o seu enunciado de forma a obter um determinado efeito de sentido, sem compromissos com psicologismos e com concepções simplórias de língua e linguagem.

Para Discini (2003), o estilo não é o "algo a mais", o belo, o raro, o desvio. Para a autora, o estilo é o homem quando se pensa num efeito de sentido de individualidade, com corpo, voz e caráter, construído pelo próprio discurso e que tem um modo próprio de presença no mundo: um ethos.

Para Moliné (1993, p. 7-8),

On pourrait également prendre pour base des situations d'énonciation fondamentales, qui relèvent des principaux schémas de situation social entre celui qui parle et ceux à qui il s'adresse: demander, répondre, conseiller, défendre, expliquer, séduire, émouvoir, avec tout la gamme des sentiments, éprouvés par soi-même ou par ses interlocuteurs, réels ou feints, qui peuvent colorer ces activités verbales. ${ }^{1}$

Ao pensar o estilo, remetemos à ideia de enunciação que leva à reflexão das possibilidades de entendimento do discurso, considerando o estilo do enunciador que, consequentemente, leva o enunciatário a construir uma imagem daquele que enuncia.

\section{0 ethos discursivo em Cada vez mais...}

Passo à análise do poema que constitui o corpus deste artigo.

\footnotetext{
1 Tradução livre do francês: "Nós poderíamos também tomar como base a situações de enunciação que estejam dentro dos principais padrões de situação social entre aquele que fala e aqueles a quem ele se dirige: perguntar, responder, aconselhar, defender, explicar, motivar, entusiasmar com toda a gama de sentimentos vivenciados por si mesmo ou por seus interlocutores, reais ou imaginados, que podem tornar estas atividades verbais mais significativas", Moliné (1993, p. 7-8).
} 
EID\&A - Revista Eletrônica de Estudos Integrados em Discurso e Argumentação, Ilhéus, n. 13, jan/jun.2017.

“CADA VEZ MAIS"

A cada vez queremos mais.

Rumo ao céu

Mais que o olhar

mais que o sorriso

mais que o cheiro

mais que a voz.

A saliva

e o calor de um sentimento

atroz.

Queremos mais que os copos

cheios,

mais inteiros que ao meio.

Mais desejo

mais mão

mais beijo.

Queremos mais que a rua

a água da minha língua

na tua pele nua.

queremos mais que estradas.

Elevadores

degraus

escadas.

Queremos mais que rabiscos, desenhos

Tatuagens.

Queremos mais que

sacanagem.

Para dentro de nós,

pequenas viagens.

Lucidez,

goles gelados de cerveja

embriaguez.

Queremos praia

mais apego

sossego.

Queremos tudo um do outro nas loucuras que a gente faz.

De querer queremos sempre

Cada vez mais.

O poema é escrito em 37 versos, distribuídos em 5 estrofes, com tom confessional. Do ponto de vista semântico, o poema é a indicação de um desejo incessante, "cada vez mais" intenso, exposto através de vários elementos que surgem ao longo dos versos, sugerindo a busca por um sentimento "cada vez mais" forte; há um desejo de cumplicidade do enunciador e de seu enunciatário. Daí a presença da primeira pessoa do plural, marcada no verbo querer ("queremos"), presente em todas as estrofes do poema. Esse recurso, assim, contribui para a adesão do destinatário ao discurso presente em cada verso, pois aquele acaba por se ver nessa busca incessante. Essa pessoa do discurso - 1a. pessoa do plural - procura imprimir a ideia compartilhada por seus leitores ou ouvintes, representam um pensamento coletivo.

Vale lembrar que querer é ambicionar, projetar algo; é procurar fazer com que algo aconteça; é concentrar a energia e aplicar sua vontade para obter aquilo que se deseja, ou seja, a transcendência, a realização com a pessoa amada, mas num plano não só material, por isso, "Queremos tudo um do outro / nas loucuras que a gente faz."

Como apontei anteriormente, o quadro cênico compõe-se da cena literária como cena englobante, e da poesia lírica como a cena genérica. A 
EID\&A - Revista Eletrônica de Estudos Integrados em Discurso e Argumentação, Ilhéus, n. 13, jan/jun.2017.

cenografia constitui-se em um tom confessional do enunciador, a confissão de um querer, de um desejar que ultrapassa os limites do mundo material e que se configura "nas loucuras que a gente faz", como o próprio enunciador enuncia na última estrofe do poema. Essa cenografia constrói um mundo que valoriza o mundo sonhado, do desejo, muitas vezes imaginado pelos amantes, implicando a presença de um ethos discursivo do sujeito que deseja realizar-se com o ser amado, completar-se além do plano físico, em uma supra realidade da qual está inserido; um mundo que esteja além daquele que vivencia o dia a dia.

Maingueneau propõe o conceito de cenas validadas. Segundo o autor,

[...] de fato, as obras podem basear suas cenografias em cenários de enunciação já validados, quer se trate de outros gêneros literários, quer de outras obras, de situações de comunicação de ordem não literária (cf. a conversa mundana, a tal da camponesa, o discurso jurídico). "Validado" não significa valorizado, mas já instalado no universo de saber e de valores do público. (MAINGUENEAU, 2001, p. 126).

Nesse sentido, podemos afirmar que o poema valida da cena do ser humano que está em constante busca, que motiva sua existência, dando sentido para a vida. Desde a Antiguidade, entende-se o homem como um ser incompleto, cuja busca pela satisfação, pela plenitude é algo constante em sua existência.

Há um ethos discursivo construído a partir de um enunciador, o qual é constituído por um conjunto de características psicológicas e ideológicas, além de um papel frente ao enunciatário. Ele é uma maneira de dizer que remete a uma maneira de ser.

Fica claro que o ethos discursivo que se constitui no poema se identifica com seu enunciador. Esse fato pode ser mostrado pelo verbo em primeira pessoa do plural ("queremos"), como já apontado. Por um conjunto de traços vão se constituindo os tons que caracterizam esse ethos, como um sujeito que se completa no e com o outro em seu fazer, em seu sentir.

\section{Mais desejo \\ Mais mão \\ Mais beijo}

Esses três versos sugerem o contato físico entre os amantes, que é uma constante nos versos de Bró. É possível perceber a repetição de palavra (no caso deste poema, uma expressão), em uma mesma posição, no caso, "mais (que)", constitui-se em um recurso frequente no poema; procura-se enfatizar o desejo constante do enunciador. Esse mecanismo linguístico-discursivo enfatiza o descontentamento do enunciador, caracterizando a busca 
EID\&A - Revista Eletrônica de Estudos Integrados em Discurso e Argumentação, Ilhéus, n. 13, jan/jun.2017.

incessante por algo que esteja além daquilo que faça parte de seu cotidiano. Em cada uma das quatro estrofes que compõem o poema, essa sequência de enumeração é quebrada com um sentimento de sensualidade do enunciador, como algo que lhe trouxesse a realização plena tão desejada.

E essa quebra das enumerações feitas pelo enunciador permite a construção do ethos discursivo de um sujeito marcado pela sensualidade, como demonstram os versos:

\footnotetext{
Queremos mais que a rua

a água da minha língua

na tua pele nua.
}

A língua, de acordo com Chevalier \& Cheerbrant (1995, p. 549), "é considerada como chama. Possui a forma e a mobilidade desta. Destrói e purifica". E completa o autor: "Para os bambaras, a língua é, com a perna, o nariz e o sexo, um dos quatro órgãos de que depende o bom funcionamento do corpo social [...]. Órgão da palavra, é considerada a criadora dos verbos, imbuída de um poder de fecundação da mesma categoria da chuva, do sangue [...], da saliva, que é o veículo do verbo" (CHEVALIER \& GHEERBRANT, 1995, p. 550).

O estilo, de acordo com Discini (2003), é ethos, porque implica um modo de dizer. Nesse sentido, o enunciador de "Cada vez mais" assume um estilo que leva o enunciatário a construir a imagem deste que enuncia. A questão estilística tem os efeitos discursivos, evidenciando o ethos do enunciador. Segundo Amossy (2005), o estilo, o conhecimento de mundo e as ideologias implícitas em um discurso são capazes de promover a constituição do ethos discursivo do enunciador.

Nesse sentido, o primeiro verso do poema já nos oferece o tema: "A cada vez queremos mais" e, a partir do segundo verso, o enunciador enumera uma série de elementos que ainda não os satisfazem - nós - primeira pessoa do plural colocada ambiguamente, pois pode ser nós, ele enunciador e o ser amado, mas também, ele, o enunciador e seu leitor, tendo em vista que o ser humano também está em constante busca pela plenitude de seus sentimentos, de suas paixões, de sua realização material e espiritual.

De acordo com Goldstein, "as figuras sonoras de repetição não têm um sentido por si próprias, mas somam seu efeito à significação do poema, [...]" (GOLDSTEIN, 1990, p. 52). Na primeira estrofe, por exemplo, há o predomínio do fonema vocálico /o/, que caracteriza uma assonância. Segundo Martins 
EID\&A - Revista Eletrônica de Estudos Integrados em Discurso e Argumentação, Ilhéus, n. 13, jan/jun.2017.

(1989, p. 32), "a série posterior [ao se referir aos fonemas /o/ e /u/] tem a possibilidade de imitar sons profundos, cheios, graves, ruídos surdos, e sugere ideia de fechamento, redondeza, escuridão, tristeza, medo, morte", no caso, possibilita a construção do ethos de um sujeito triste, insatisfeito, buscando sentimentos profundos, que transcendem a existência para sua realização. Essa assonância combina com a aliteração na fricativa $/ \mathrm{s} /$, sugerindo $\mathrm{o}$ movimento, que é feito pelo enunciador, em busca de sua realização. E essa fricativa se faz presente em todas as estrofes do poema, reiteradamente.

Há de se considerar, ainda, a repetição da expressão "mais (que)". No decorrer do poema, ela tem a função de evidenciar a comparação entre algo que existe, mas que o enunciador deseja mais, levando-nos a construir a imagem de um sujeito insatisfeito, em constante busca de algo que o satisfaça. A expressão acaba por se caracterizar como um elemento argumentativo, uma vez que privilegia a relação intersubjetiva e, ao comparar, leva à identificação entre enunciador e enunciatário. Como aponta Amossy (2005, p. 122), "a argumentação, apresente ela ou não vontade manifesta de conduzir à aprovação, é sempre parte integrante do discurso em situação".

Discini (2003, p. 23) afirma que "as marcas da enunciação enunciada são levadas em conta na medida em que, compactadas em vetores estilísticos, fundam a imagem do enunciador [...]". Isso significa dizer que as marcas linguísticas, abordadas no âmbito do estilo, também nos levam à constituição do ethos discursivo daquele que enuncia.

A presença dos pronomes possessivos - minha, tua - configura a imagem de um sujeito que se põe a declarar-se para alguém que deseja, constituindo o ethos discursivo de um ser desejoso, tomado pela paixão, a qual transcende $o$ plano físico, pois, juntos, "Queremos praia, / mais apego / sossego / Rumo ao céu / queremos mais que estradas. / Elevadores / degraus / escadas". Cria-se a imagem de elevação, conseguida a partir da paixão que consome os amantes, ou, como dito anteriormente, o próprio leitor. É a busca constante desse sujeito pela transcendência.

Nesses versos, fica clara a ideia de ascensão, pois o enunciador busca a elevação, a dimensão superior ("céu"), visto por todos e, ao mesmo tempo, com intensa profundidade interior. A escada, segundo Chevalier \& Cheerbrant (1995, p. 378), é o "símbolo por excelência da ascensão e da valorização, ligando-se à simbólica da verticalidade". É nessa busca pela ascensão que o enunciador encontra o sossego, a tranquilidade. Constrói-se a imagem de um 
EID\&A - Revista Eletrônica de Estudos Integrados em Discurso e Argumentação, Ilhéus, n. 13, jan/jun.2017.

sujeito capaz de transpor-se além do material para o encontro da felicidade. $\mathrm{E}$ esse movimento é ratificado, ainda, pela forte presença da aliteração do fonema $/ \mathrm{s} /$, caracterizado como construtivos sonoros, que sugerem $\mathrm{o}$ movimento, como já apontei anteriormente.

O poema denota a constituição do ethos discursivo de um sujeito que está numa busca constante por uma paixão que o leve a transcender o mundo material no qual se encontra, já que "queremos mais (que) desejo/ mais mão/ mais beijo./ Queremos mais que a rua/ a água da minha língua/ na tua pele nua", versos da segunda estrofe.

Esse querer "cada vez mais" caracteriza quase que uma não aceitação, uma não satisfação com o presente e, por isso, volta-se "para dentro de nós / pequenas viagens", a fim de realizar o que não conseguem no mundo exterior. Esse voltar para o interior é uma forma de se elevar "rumo ao céu", em busca da plenitude, para alcançar o "mais que" tão desejado pelo enunciador e pelo ser amado. É como se houvesse a oportunidade de realizarse plenamente, pois "Queremos tudo um do outro / nas loucuras que a gente faz". Permitem-se às (re)construções de sentimentos para encontrar novos sentidos para a vida. Mais uma vez deparamos com a ambiguidade, pois o leitor também quer se encontrar nas loucuras dos versos do poeta. Trata-se de mais um recurso linguístico-discursivo argumentativo, que procura persuadir o leitor, a fim de envolvê-lo por meio da palavra.

A argumentação assenta-se não sobre o que é verdadeiro, mas ao que é verossímil - isto é, concebe-se a argumentação como espaço de interação entre sujeitos que buscam modificar seus pontos de vista, com base naquilo que eles podem aceitar como valores. Procura-se construir um ethos discursivo de um sujeito com o qual o enunciatário (leitor) se identifique; o enunciador procura construir uma imagem de si que leva em conta o enunciatário, isto é, um ser humano que também vive a insatisfação da realidade e que está em constante busca de si.

Para Maingueneau (2016), existem três dimensões do ethos discursivo categórica, exponencial e ideológica - que interagem fortemente. A primeira abrange diversos fatores, dentre eles os papeis discursivos ou estatutos extradiscursivos. Nas palavras do autor, "os papeis discursivos são aqueles relacionados à atividade de fala: animador, contador de história, pregador. Os estatutos extradiscursivivos podem ser de natureza muito variada pai de família, funcionários, médicos, camponês, americanos, solteiros etc" (MAINGUENEAU, 
EID\&A - Revista Eletrônica de Estudos Integrados em Discurso e Argumentação, Ilhéus, n. 13, jan/jun.2017.

2016, p. 15). No caso do poema de "Cada vez mais", o ethos discursivo categórico é marcado por um sujeito que busca uma realização; é a voz do ser humano insatisfeito, mas apaixonado e, com o outro, quer se completar.

Em relação à dimensão exponencial, para Maingueneau (2016, p. 15), evidenciam-se "as caracterizações sócio-psicológicas estereotipadas, associadas às noções de incorporação e de mundo ético: bom senso e lentidão do campo, dinamismo do jovem executivo".

A dimensão ideológica se refere "a alguns posicionamentos dentro de um campo: feminista, de esquerda, conservador ou anticlericais; em um campo político, romântico, ou naturalista; em um campo literário etc (MAINGUENEAU, 2016, p. 15). Em "Cada vez mais", evidencia-se o posicionamento de um sujeito amante, em busca da realização de seu sentimento amoroso com o ser amado, mas em uma outra esfera diferente da realidade em que se encontra.

\section{Palavras (quase) finais...}

Ao longo do artigo, procurei mostrar os efeitos expressivos presentes no poema "Cada vez mais", de Rodrigo Bró, considerando os aspectos relativos à construção do ethos discursivo do enunciador.

O discurso é forma de socializar um pensamento, uma ideologia e apresenta uma tomada de posição e, consequentemente, constitui-se em uma instância geradora de argumentação. E, nesse sentido, o ethos caracteriza-se como um elemento argumentativo, pois o enunciador constrói uma imagem de si como estratégia capaz de levar o enunciatário a voltar-se para uma subjetividade. $O$ ethos é a instância do discurso revelada por uma composição que deixa à mostra uma maneira subjetiva de lidar com a realidade.

O artigo trouxe na segunda parte a análise do poema, evidenciando as relações das organizações do poema, assim como o estilo que reconstrói um corpo, uma voz e um caráter do enunciador (MAINGUENEAU, 2008).

A análise trouxe considerações que levaram à compreensão de como se dá a construção do ethos discursivo no discurso literário a partir do poema que constituiu o corpus deste artigo. Como afirma Fiorin (2014, p. 54), "as teorias do discurso devem levar em conta dois aspectos: de um lado, a organização das unidades discursivas transfrásticas; de outro, o modo de funcionamento real do discurso, ou seja, seu caráter dialógico". 
EID\&A - Revista Eletrônica de Estudos Integrados em Discurso e Argumentação, Ilhéus, n. 13, jan/jun.2017.

Pelos elementos levantados na análise, é lícito afirmar que o poema apresenta o ethos de um enunciador que evidencia a busca incessante do ser humano, uma postura de libertação do homem para um mundo de vai além do material.

O ethos discursivo possibilita identificar a função enunciativa do enunciador, no caso o eu lírico e sua relação como tema, pois a cenografia mostra a criação de um sujeito otimista não com o mundo sensível, mas com a realização plena em um mundo que transcende a realidade em que está inserido.

\section{Referências}

AMOSSY, Ruth. Introdução: da noção retórica de ethos à análise do discurso. In: (Org.). Imagens de si no discurso: a construção do ethos. Trad. Dilson F. da Cruz, Fabiana Komesu e Sírio Possenti. São Paulo: Contexto, 2005. p.9-28.

BAKHTIN, Mikail. Apontamentos de 1970-1971. In: . Estética da criação verbal. 4.ed. Trad. Paulo Bezerra. São Paulo: Martins Fontes, 2003. p.367- 392.

CARVALHO, Fabiana Castro. Interdiscurso, cenas de enunciação e ethos discursivo em canções de Ataulfo Alves. PERcursos Linguísticos, Vitória, v. 3, n. 1, p. 82-98, 2011. CHEVALIER, Jean; GHEERBRAINT, Alain. Dicionário de símbolos. 9. ed. Trad. Vera da Costa e Silva et al. Rio de Janeiro: José Olympio Editora, 1995.

CRUZ, Dilson Ferreira da. $O$ ethos dos romances de Machado de Assis. São Paulo: EDUSP, 2009.

DISCINI, Norma. O estilo nos textos: história em quadrinhos, mídia e literatura. São Paulo: Contexto, 2003.

FIORIN, José Luiz. Argumentação e discurso. Revista Bakthiniana, São Paulo, n. 9, v. 1, 2014, p. 53-79.

GOLDSTEIN, Norma. Versos, sons, ritmos. 6.ed. São Paulo: Ática, 1990.

MAINGUENEAU, Dominique. 0 contexto da obra literária. Trad. Marina Appenzeller. São Paulo: Martins Fontes, 2001.

. Novas tendências em análise do discurso. Campinas: Pontes, 2005

. O discurso literário. Trad. Adail Sobral. São Paulo: Contexto, 2006.

. Gênese do discurso. Trad. Sírio Possenti. São Paulo: Parábola, 2008. 
EID\&A - Revista Eletrônica de Estudos Integrados em Discurso e Argumentação, Ilhéus, n. 13, jan/jun.2017.

. Doze conceitos em análise do discurso. Org. Maria Cecília Souza-e-Silva e Sírio Possenti. São Paulo: Parábola, 2010.

. Análise de textos de comunicação. Trad. Maria Cecília Souza-e-Silva e Décio Rocha. São Paulo: Cortez Editora, 2013.

. Discurso e análise do discurso. Trad. Sírio Possenti. São Paulo: Parábola, 2015.

. Retorno crítico sobre o ethos. In: BARONAS, Roberto; MESTI, Paula Camila; CARREON, Renata de Oliveira (Org.). Análise do Discurso: entorno da problemática do ethos, do político e de discursos constituintes. Campinas: Pontes, 2016.

MARTINS, Nilce Sant'Anna. Introdução à estilística. São Paulo: EDUSP, 1989.

MOLINÉ, Georges. Le stylistique. Paris: PUF, 1993.

POSSENTI, Sírio. Os limites do discurso: ensaios sobre discurso e sujeito. São Paulo: Parábola, 2009.

Forma de citação sugerida:

SILVA, Sandro Luis da. Argumentação, estilo e ethos discursivo no discurso literário: o poema cada vez mais, de Rodrigo Bró em foco. EID\&A - Revista Eletrônica de Estudos Integrados em Discurso e Argumentação, Ilhéus, n. 13, p. 174-190, jan/jun.2017.

Recebido em: 04/03/2017

Aprovado em: 15/05/2017 